\title{
Optokinetically Evoked Expression of Corticotropin-releasing Factor in Inferior Olivary Neurons of Rabbits
}

\author{
N. H. Barmack' and P. Errico ${ }^{1,2}$ \\ 1'Devers Eye Institute and R. S. Dow Neurological Sciences Institute, Good Samaritan Hospital and Medical Center, \\ Portland, Oregon 97209 and 'Istituto di Fisiologia Umana, Università Cattolica del Sacro Cuore, Roma, Italy, 1-00168
}

We investigated the influence of both binocular and monocular optokinetic stimulation on the expression of corticotropin-releasing factor (CRF), a neuropeptide, in inferior olivary neurons. Rabbits were placed at the center of a cylindrical optokinetic drum that rotated at a constant velocity of 5 degrees/sec, stimulating one eye in the posterior $\rightarrow$ anterior direction and the other eye in the anterior $\rightarrow$ posterior direction. After $\mathbf{4 8} \mathrm{hr}$ of optokinetic stimulation, rabbits were killed and the brains were prepared for immunohistochemistry. An antiserum to rat/human CRF was used to label brainstem sections of optokinetically stimulated rabbits. The density of CRF-specific reaction product within individual olivary neurons was analyzed with a computer-based densitometer.

Binocular optokinetic stimulation for $48 \mathrm{hr}$ caused a 20$70 \%$ increase in the optical density of "stimulated" dorsal cap neurons, measured relative to the optical density of control ("unstimulated") olivary neurons in the same histological section. This elevated expression of CRF lasted approximately $48 \mathrm{hr}$. When a delay of $18 \mathrm{hr}$ was interposed between optokinetic stimulation and death of the rabbit, during which the rabbits were deprived of pattern vision, then both dorsal caps were densely labeled. Monocular optokinetic stimulation for $\mathbf{4 8} \mathrm{hr}$ in the anterior $\rightarrow$ posterior direction caused no change in CRF expression in either dorsal cap if the rabbit was immediately killed. However, following monocular anterior $\rightarrow$ posterior stimulation, the dorsal cap contralateral to the "null-stimulated" eye was densely labeled if the rabbit was deprived of pattern vision for $18 \mathrm{hr}$ prior to death. We infer that stopping prolonged "null stimulation" causes a rebound in activity in the stimulated dorsal cap. This "rebound" must have its origin at the level of the dorsal cap or more peripherally in the optokinetic pathway.

[Key words: corticotropin-releasing factor, inferior olive, dorsal cap, optokinetic stimulation, immunohistochemistry]

The cerebellum receives afferent information from two major classes of inputs, mossy fibers and climbing fibers. While mossy fibers originate from a number of different sources (Ito, 1984), climbing fibers originate exclusively from the contralateral in-

\footnotetext{
Received Feb. 4, 1993; revised May 3, 1993; accepted May 11, 1993.

We thank Leta Guptill for expert histological, technical, and artistic assistance. This research was supported by NEI EY04778 and the Oregon Lions Sight and Hearing Foundation. We thank Wylie Vale, Ph.D., The Clayton Foundation Laboratories for Peptide Biology, The Salk Institute, for supplying us with an antiserum for CRF (PBL rC70).

Correspondence should be addressed to Neal H. Barmack, Ph.D., R. S. Dow Neurological Sciences Institute, 1120 N.W. 20 h A Avenue, Portland, OR 97209.

Copyright (C) 1993 Society for Neuroscience $0270-6474 / 93 / 134647-13 \$ 05.00 / 0$
}

ferior olivary nucleus (Fox et al., 1967; Desclin, 1974). Each cerebellar Purkinje cell receives a projection from a single climbing fiber terminal that evokes a large EPSP, which in turn evokes multiple Purkinje cell action potentials (Granit and Phillips, 1956; Eccles et al., 1966). One of the subdivisions of the inferior olive, the dorsal cap of Kooy, consists of a group of 1500-2000 neurons that encode visual stimulation in a three-dimensional coordinate system that resembles that of the semicircular canals of the vestibular system (Simpson et al., 1981). The most caudal $500-600 \mu \mathrm{m}$ of the dorsal cap consists of a compact cluster of approximately 500 neurons that encode horizontal optokinetic stimulation. These olivary neurons are excited by posterior $\rightarrow$ anterior optokinetic stimulation of the contralateral eye and disfacilitated by anterior $\rightarrow$ posterior stimulation (Barmack and Hess, 1980a). Thesc visually responsive ncurons in the dorsal cap have a maximal sensitivity to retinal slip velocity at 1 degree/sec, and this sensitivity is reduced by $50 \%$ at 0.1 degree/ sec and at 10 degrees/sec (Barmack and Hess, 1980a). The axons of these caudal dorsal cap neurons comprise part of the visual climbing fiber projection to the contralateral flocculus and nodulus (Maekawa and Simpson, 1973; Alley et al., 1975; Maekawa and Takeda, 1976).

The visual climbing fiber projection has been implicated in the normal control and plastic modification of reflexive eye movements (Ito et al., 1976; Dufosse et al., 1978; Barmack, 1979; Barmack and Hess, 1980a,b; Barmack and Simpson, 1980; Ito et al., 1982; Watanabe, 1984). If the dorsal cap is stimulated electrically, low-velocity eye movements are evoked that outlast the duration of the electrical stimulus (Barmack and Hess, 1980b). If the dorsal cap is destroyed unilaterally, a permanent impairment in optokinetic reflexes mediated formerly by the damaged dorsal cap is induced (Barmack and Simpson, 1980). Prolonged unidirectional optokinetic stimulation at a retinal slip velocity of $1 \mathrm{degree} / \mathrm{sec}$, the velocity at which visual climbing fibers are most sensitive, evokes a prolonged "negative optokinetic afternystagmus" that can last for $100 \mathrm{hr}$ (Barmack and Nelson, 1987). These observations suggest that visual climbing fibers may, in part, be responsible for plastic cerebellar control of reflexive eye movements.

The role of visual climbing fibers in evoking plastic changes in cerebellar function may be dependent upon the synthesis and/ or expression of synaptic transmitter(s). One transmitter for these climbing fiber pathways is probably glutamate or aspartate (Wiklund et al., 1982; Matute et al., 1987). A second transmitter or neuromodulator, found in all olinary neurons, is corticotropin-releasing factor (CRF). This 41 amino acid neuropeptide, originally isolated from bovine hypothalamus, stimulates the release of proopiomelanocortin-derived peptides from the an- 
terior lobe of the pituitary gland (Vale et al,, 1981). CRF has been localized immunohistochemically to several extrahypothalamic regions of the CNS, including the inferior olive and the cerebellum (Schipper et al., 1983; DeSouza, 1987; Palkovits et al., 1987; Powers et al., 1987; Sakanaka et al., 1987a,b; Cha and Foote, 1988; Cummings et al., 1988, 1989; Mugnaini and Nelson, 1989; Barmack and Young, 1990). CRF mRNA has also been localized to the inferior olive using hybridization histochemistry (Young et al., 1986; Palkovits et al., 1987; Barmack and Young, 1990). Receptors for CRF have been identified in the cerebellum (Wynn et al., 1984; DeSouza et al., 1985; DeSouza, 1987).

If CRF were functionally important for olivocerebellar synaptic transmission or for modification of synaptic transmission, then one would expect that both the transcription of CRF mRNA and the expression of CRF in olivary neurons would be related to neuronal activity. Previously we have shown that optokinetic stimulation evokes large (10-fold) increases in CRF mRNA concentrations in stimulated olivary neurons (Barmack and Young, 1990). In the present experiment we have examined the expression of CRF in olivary neurons related to optokinetically evoked activity. We have used optokinetic stimulation to alter the activity of neurons in the caudal dorsal cap of the inferior olive. Using quantitative immunohistochemistry, we have investigated the influence of this alteration in activity on CRF expression.

\section{Materials and Methods}

Surgical procedures. Thirteen pigmented rabbits, weighing $1.0-2.0 \mathrm{~kg}$, were the subjects in this experiment. In preparatory operations the rabbits were anesthetized with intramuscular injections of ketamine hydrochloride $(50 \mathrm{mg} / \mathrm{kg})$, xylazine $(6 \mathrm{mg} / \mathrm{kg})$, and acepromazine maleate $(1.2 \mathrm{mg} / \mathrm{kg})$ (Harkness and Wagner, 1989). Each rabbit's head was aligned in a stereotaxic apparatus so that the lambda suture was 1.5 $\mathrm{mm}$ above the bregma suture. Two stainless steel screws (8-32) were anchored to the calvarium with four smaller peripherally placed stainless steel screws (2-56) and dental cement. The two larger screws mated with devices that were used to restrain the rabbit's head during optokinetic stimulation.

Head restraint during optokinetic stimulation. For long-term optokinetic stimulation, rabbits were placed in a plastic restrainer (Nalge Co.) with an adjustable neck piece. The restrainer had a stainless steel grid floor elevated above a plastic, removable collection pan. The restrainer was mounted on a pedestal in the center of an optokinetic cylinder that had a diameter of $110 \mathrm{~cm}$ and a height of $115 \mathrm{~cm}$. The head of the rabbit was aligned within the optokinetic cylinder in the horizontal plane by a spring-loaded flexible coupling that was attached to the rabbit restrainer and that had holes that mated with the surgically implanted bolts on the calvarium. This flexible coupling system permitted movements of the head in the sagittal plane, but prevented the potentially confounding influence of optokinetically evoked horizontal head movements. The flexible coupling also maintained the head in a relatively constant orientation with respect to earth horizontal (Barmack and Nelson, 1987; Barmack and Young, 1990). The alignment of the head within the optokinetic cylinder was critical, since even slight misalignments could result in vertical as well as horizontal optokinetic stimulation.

This method of restraint causes no pressure on any part of the body. It permits partial movement of the head in the sagittal plane, and it permits vertical and lateral movement of the body. The rabbit is able to maintain its normal posture with all four paws in contact with the support surface. The EKG and respiratory rate of several rabbits were monitored during the experiment and remained within the normal range of $180-220 \mathrm{beats} / \mathrm{min}$ and $30-50 \mathrm{breaths} / \mathrm{min}$. Both rates accelerated if the rabbit was disturbed from its normal state of quiet rest by an unexpected stimulus. During optokinetic stimulation the rabbits were removed from the apparatus every $8 \mathrm{hr}$, weighed, and given food and water. They were returned to the testing apparatus after $20-30 \mathrm{~min}$. The feeding period was terminated only when the rabbits had finished feeding and had withdrawn to the rear of the feeding cage. This feeding regimen of 20-30 min every $8 \mathrm{hr}$ was sufficient for the rabbits to maintain body weight, which was measured three times each day. Rabbits easily adapted to this modified restraint, and evinced no behavioral signs that would indicate a reluctance to resubmit to restraint after a brief hiatus for food and water.

One might expect that prolonged optokinetic stimulation would induce nausea in the stimulated rabbits. However, rabbits lack an emetic reflex. Furthermore, their ingestion of ordinary rabbit food was undiminished by prolonged stimulation. Prolonged stimulation did produce some postural changes when the rabbits were released from the optokinetic drum. These changes included transient circling behavior in a direction opposite to the drum rotation. This circling behavior disappeared after 1-3 min and was replaced by slow ocular and head nystagmus that lasted 1-30 min. This nystagmus could be suppressed by rabbits as they were eating and drinking.

Optokinetic stimulation. The inside wall of the optokinetic cylinder was a contour-rich pattern that rotated at an angular velocity of 5 degrees/sec (Fig. 1 $A$ ). Optokinetic stimulation initially evokes eye movements with an average velocity of 4 degrees/sec, thereby creating a retinal slip velocity of 1 degree/sec (Erickson and Barmack, 1980). In the present experiment we employed four different kinds of optokinetic stimulation (Fig. 1C): (1) for binocular optokinetic stimulation, the optokinetic drum rotated at 5 degrees/sec about the rabbit for a specified time in the posterior $\rightarrow$ anterior direction with respect to the left eye $\left(\mathrm{P} \rightarrow \mathrm{A}_{\mathrm{L}}\right)$ (Fig. $\left.1 C_{l}\right) ;(2)$ for binocular control, the optokinetic drum rotated about the rabbit, but both eyes of the rabbit were occluded with translucent Ping-Pong balls (Fig. $1 C_{2}$ ); (3) for excilatory monocular optokinetic stimulation, the left eye was stimulated in the posterior $\rightarrow$ anterior direction $\left(P \rightarrow A_{L}\right)$, exciting the right dorsal cap, while the right eye was occluded (Fig. $1 C_{3}^{\prime}$ ); and (4) for disfacilitatory monocular optokinetic stimulation, the right eye was stimulated in the anterior $\rightarrow$ posterior direction $\left(A \rightarrow P_{R}\right)$, disfacilitating the left dorsal cap, while the left eye was occluded (Fig. 1 $C_{4}$ ). All optokinetic stimulus durations were for 48 $\mathrm{hr}$. This duration was previously shown to cause a four- to sevenfold increase in CRF mRNA in "stimulated" dorsal cap neurons (Barmack and Young, 1990).

$C R F$ immunohistochemistry. At the conclusion of the experimental procedures the rabbits were deeply anesthetized with intramuscular injections of pentobarbital $(60 \mathrm{mg} / \mathrm{kg})$ and perfused with a two-step procedure (Sloviter et al., 1989). The rabbit was perfused transcardially with $2 \%$ paraformaldehyde in $0.1 \mathrm{~m}$ sodium acetate buffer $\mathrm{pH} 6.5,4^{\circ} \mathrm{C}$, for $3 \mathrm{~min}$. This first fix was followed by $2 \%$ paraformaldehyde, $0.1 \%$ glutaraldehyde in $0.1 \mathrm{M}$ sodium borate buffer $\mathrm{pH} 8.5,4^{\circ} \mathrm{C}$, for $30 \mathrm{~min}$. After storage overnight at $4^{\circ} \mathrm{C}$, without rinsing, the brain was removed and cryoprotected with $10 \%, 20 \%$, and $30 \%$ sucrose in $0.1 \mathrm{M}$ sodium phosphate buffer $\mathrm{pH} 7.4$ (PBS).

The caudal brainstem was blocked and mounted on a piece of cork with embedding compound and then frozen by immersion in isopentane cooled with dry ice. Frozen sections were cut $(30-40 \mu \mathrm{m})$ on a cryostat. Every tissue section through the caudal inferior olive was saved and washed overnight in $0.1 \mathrm{~m}$ Tris-buffered saline, $\mathrm{pH} 7.6$ (TBS). Immunohistochemistry was performed on free-floating sections. After washing the sections in $0.1 \mathrm{M}$ PBS $\mathrm{pH} 7.4$ for $5 \mathrm{~min}$, and in $0.05 \mathrm{M}$ and 0.025 M PBS for 2-3 min, endogenous peroxidase activity was reduced with a $10 \mathrm{~min}$ rinse in $0.05 \% \mathrm{H}_{2} \mathrm{O}_{2}$. Further washes in $0.025 \mathrm{M}, 0.05 \mathrm{M}$, and $0.1 \mathrm{M}$ PBS were performed, followed by three $5 \mathrm{~min}$ changes of TBS. The sections were pretreated at room temperature in $20 \%$ normal goat serum (NGS), $2 \%$ bovine serum albumin (BSA), $0.5 \%$ Triton $\mathrm{X}-100$ in TBS for $4 \mathrm{hr}$, changing the solution every hour. After rinsing with three 10 min changes of TBS, the sections were incubated overnight at $4^{\circ} \mathrm{C}$, with a rabbit $\alpha$-rat/human CRF serum (PBL rC70, provided by Dr. W. Vale, The Salk Institute) used at 1:2000 dilution in 2\% BSA, 20\% NGS, $0.5 \%$ Triton-X 100 and $0.1 \%$ sodium azide in TBS. The following day, the sections were rinsed with three 10 min changes of TBS and incubated for $1 \mathrm{hr}$ in freshly prepared goat $\alpha$-rabbit, affinity-purified, secondary antibody, diluted $1: 100$ in $2 \%$ BSA, $20 \%$ NGS, $0.2 \%$ Triton $X-100$ in TBS. The tissue sections were rinsed again and incubated for $90 \mathrm{~min}$ in rabbit peroxidase-antiperoxidase (PAP) diluted 1:50 in 2\% BSA, 20\% NGS, $0.2 \%$ Triton $X-100$ in TBS. The sections were washed in TBS as before and the incubations in the secondary antibody and PAP were repeated. Finally, the sections were treated for $10 \mathrm{~min}$ in $0.05 \% 3,3^{\prime}$ diaminobenzidine tetrahydrochloride and $0.02 \% \mathrm{H}_{2} \mathrm{O}_{2}$ in TBS. After three final rinses in PBS, the sections were mounted on slides, dried, 

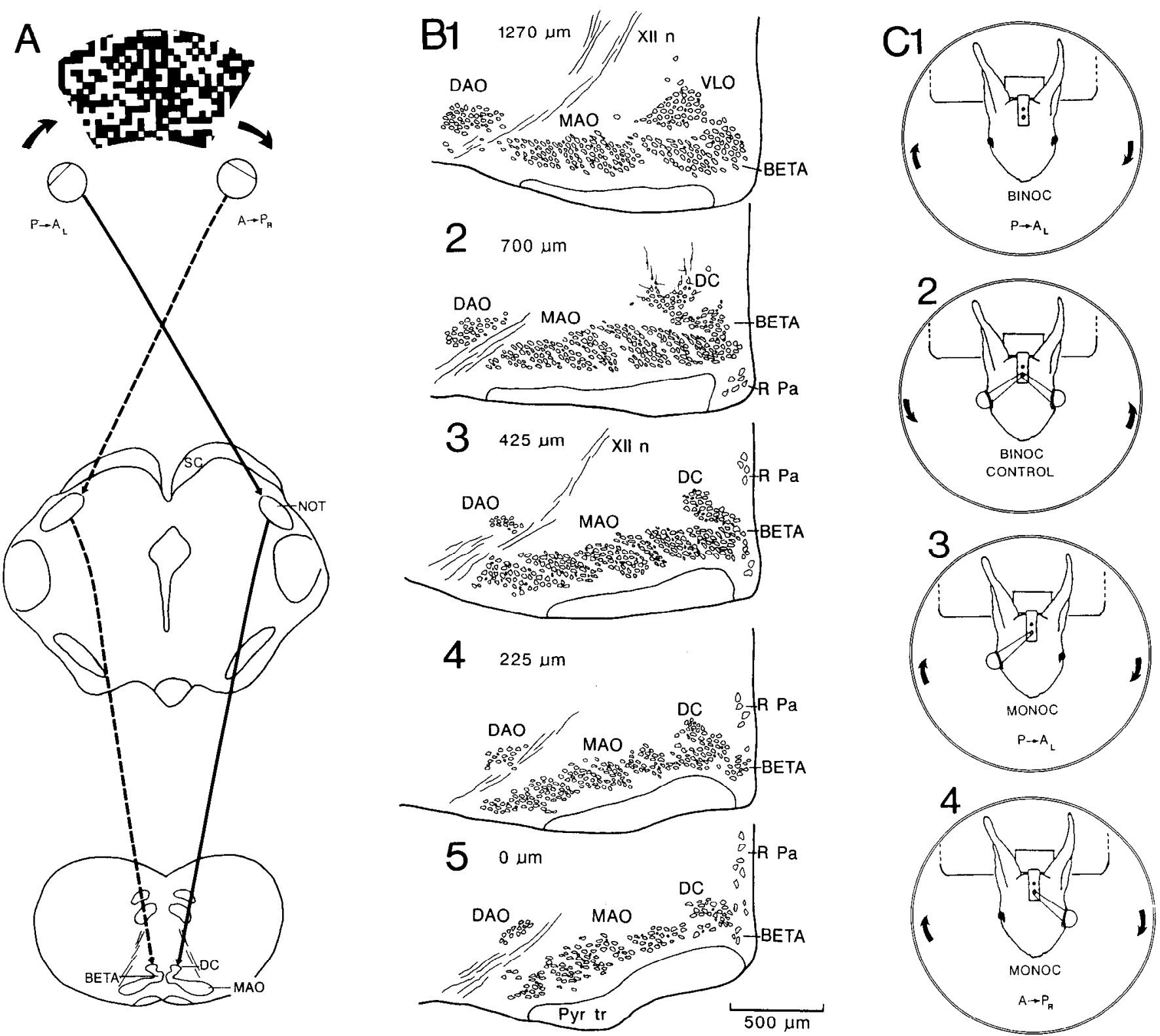

Figure 1. Illustration of the visual projections to the dorsal cap of the inferior olive and of the optokinetic stimulus conditions used to regulate the expression of CRF. A, Illustration of the anatomical pathways activated by binocular optokinetic stimulation. Directionally selective ganglion cells project to the contralateral nucleus of the optic tract (NOT). This nucleus, in turn, projects to the ipsilateral dorsal cap. During binocular optokinetic stimulation, posterior $\rightarrow$ anterior stimulation of the left eye $\left(P \rightarrow A_{L}\right)$ excites olivary neurons in the right caudal dorsal cap. Conversely, anterior $\rightarrow$ posterior stimulation of the right eye $\left(A \rightarrow P_{R}\right)$ causes disfacilitation of the left dorsal cap. $B_{t}-B_{5}$, Illustration of serial cross sections through the left caudal inferior olive. The distances between each cross section are indicated. The most caudal aspect of the dorsal cap, not the most caudal aspect of the inferior olive, is indicated arbitrarily at $0 \mu \mathrm{m}\left(B_{s}\right)$. $C_{I}-C_{4}$, Optokinctic stimulus conditions. 1 , Binocular optokinetic stimulation; the optokinetic drum rotated at 5 degrees/sec about the rabbit for a specified time in the posterior $\rightarrow$ anterior direction with respect to the left eye $\left(P \rightarrow A_{L}\right) .2$, Binocular control; the optokinetic drum rotated about the rabbit, but both eyes of the rabbit were occluded with translucent Ping-Pong balls. 3, Excitatory monocular optokinetic stimulation; the left eye was stimulated in the posterior $\rightarrow$ anterior direction, exciting the right dorsal cap, while the right eye was occluded. 4, Disfacilitatory monocular optokinetic stimulation; the right eye was stimulated in the anterior $\rightarrow$ posterior direction, disfacilitating the left dorsal cap, while the left eye was occluded. $B E T A$, beta nucleus; $D A O$, dorsal accessory olive; $D C$, dorsal cap; $M A O$, medial accessory olive; $N O T$, nucleus of the optic tract; $P y r t r$, pyramidal tract; $R P a$, raphe pallidus nucleus; $S C$, superior colliculus; $V L O$, ventrolateral outgrowth; $X I I n$, hypoglossal nerve.

cleared, and coverslipped. Control sections were processed by omitting the incubation with the primary antibody.

Quantification of CRF immunohistochemistry. The density of CRF immunostaining in the inferior olive was measured in individual neurons using a video counting microdensitometer (R\&M Biometrics, Inc.). Each of 10 neurons in a particular histological section was outlined at high magnification on a video display $(512 \times 482$ pixels $)$ using a light pen. Each pixel had a range of 256 values. The optical density of each of the 10 olivary neurons was measured in both the left and right dorsal caps. In the same histological section, control measurements of the optical density of 10 olivary neurons in the left and right medial accessory olives was also obtained. These measurements were repeated in histological sections at three different caudal-rostral levels in the caudal inferior olive (Fig. $1 B$ ). Thus, the optical density of four groups of olivary neurons, 30 neurons/group, was measured. The total areas for cells in each of these groups deviated by less than 5\%. The upper and lower pixel "thresholds" for each tissue section were selected so the densitometer was not saturated for any of the selected neurons in 
A1

A

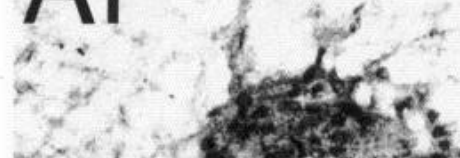

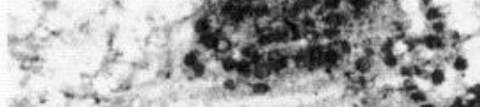

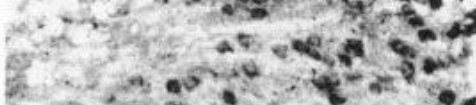

$-4.92^{2}=x^{2} x^{2}$

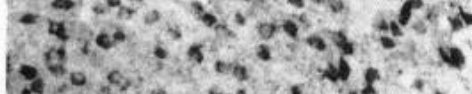

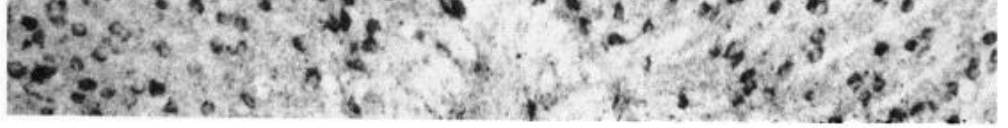

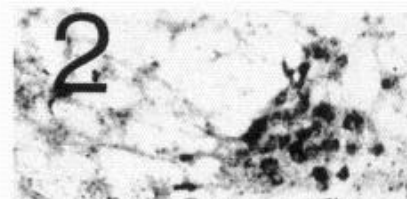

3. $x^{2}=0.5$

$5+2=0=2+2$

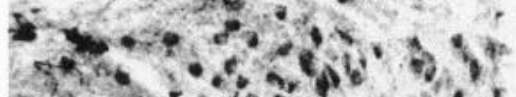

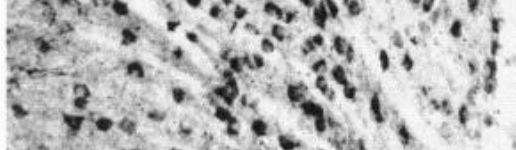

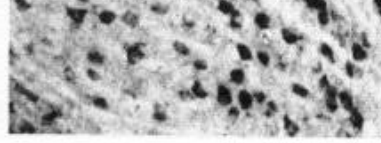
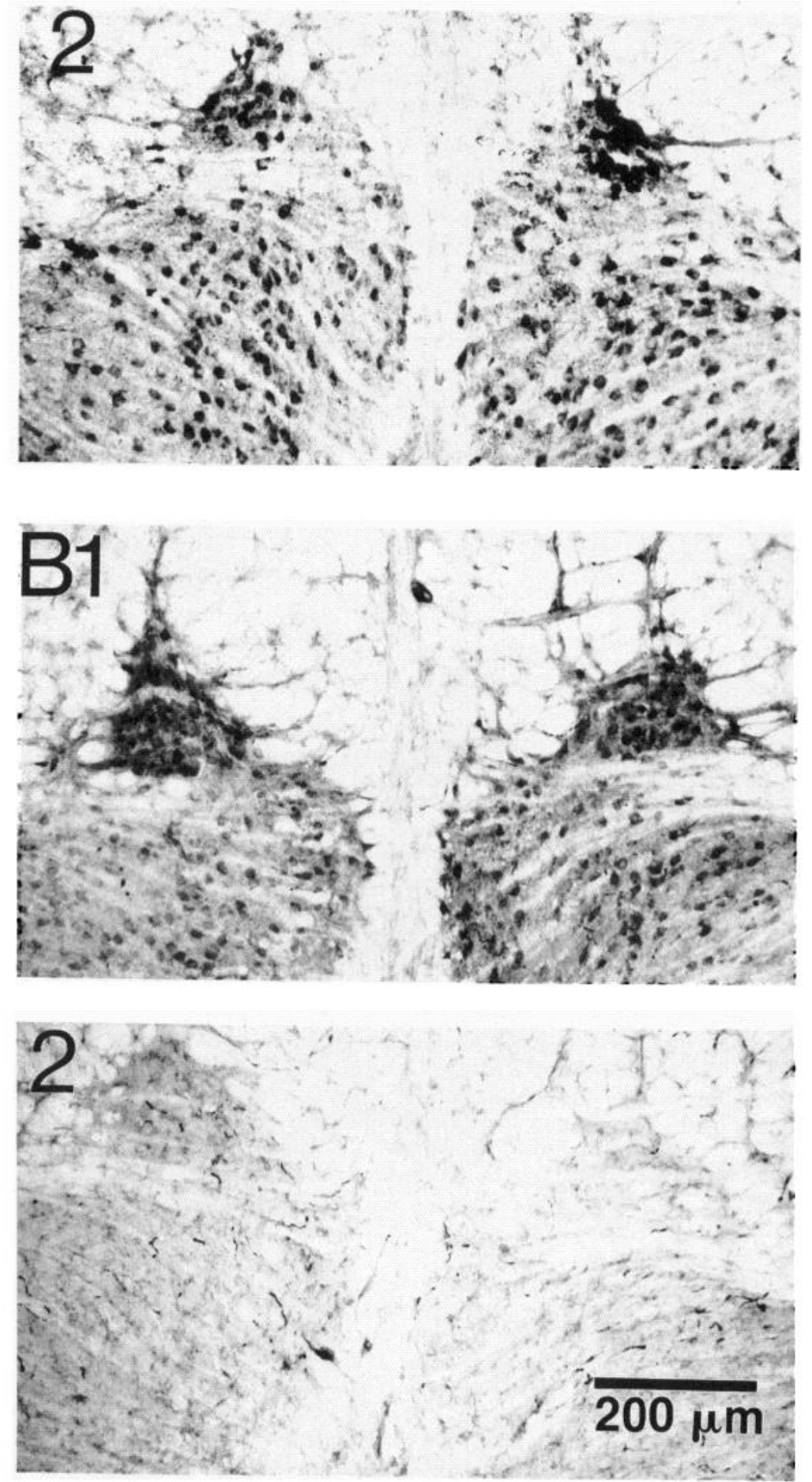

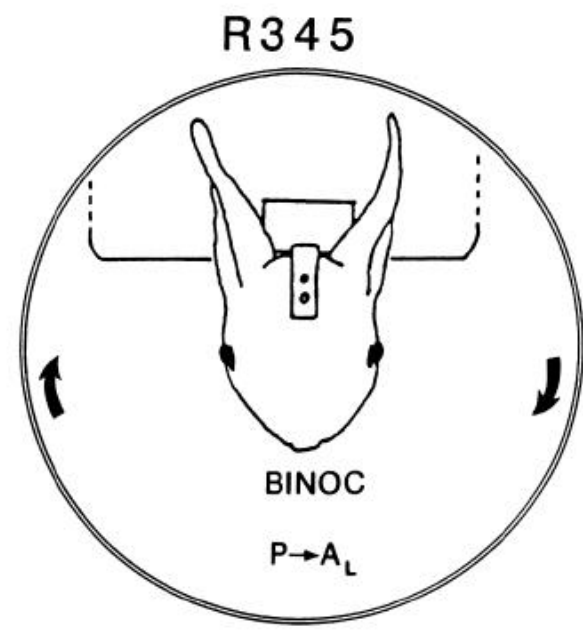

48 Hours OKS

0 Hours Post-OKS

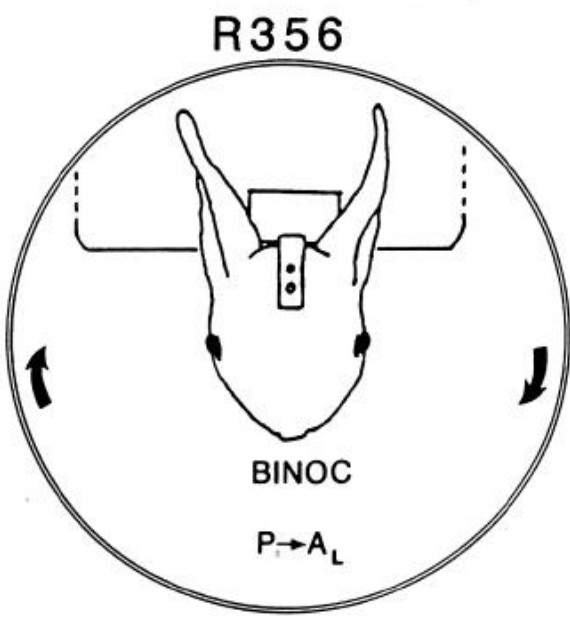

48 Hours OKS

48 Hours Post-OKS 
Table 1. Measurements of optical density in CRF-stained olivary neurons, percentage \pm SEM

\begin{tabular}{|c|c|c|c|c|c|}
\hline \multirow[b]{2}{*}{ Animal } & \multirow[b]{2}{*}{ Stimulus conditions } & \multicolumn{2}{|l|}{ Dorsal cap } & \multicolumn{2}{|c|}{ Medial accessory olive } \\
\hline & & Left & Right & Left & Right \\
\hline R358 & $48^{\prime} / 0^{2}$ & $123 \pm 2^{a, b}$ & $177 \pm 2^{c}$ & $100 \pm 2$ & $103 \pm 1$ \\
\hline R345 & $48^{1} / 0^{2}$ & $115 \pm 2^{b}$ & $157 \pm 3^{c}$ & $100 \pm 2$ & $103 \pm 2$ \\
\hline R367 & $48^{1 / 16^{3}}$ & $104 \pm 2^{b}$ & $163 \pm 4^{c}$ & $100 \pm 1$ & $104 \pm 2$ \\
\hline R352 & $48^{1 / 16^{3}}$ & $116 \pm 3^{b}$ & $175 \pm 4^{c}$ & $100 \pm 3$ & $102 \pm 3$ \\
\hline R351 & $48^{1 / 16^{3}}$ & $113 \pm 2^{b}$ & $138 \pm 1^{c}$ & $100 \pm 2$ & $99 \pm 5$ \\
\hline R357 & $48^{1 / 18^{4}}$ & $160 \pm 3^{a}$ & $160 \pm 4^{c}$ & $100 \pm 1$ & $103 \pm 3$ \\
\hline R361 & $48^{1 / 18^{4}}$ & $118 \pm 3^{a}$ & $117 \pm 3^{c}$ & $100 \pm 1$ & $100 \pm 1$ \\
\hline R362 & $48^{1 / 18^{4}}$ & $121 \pm 2^{a}$ & $134 \pm 2^{c}$ & $100 \pm 1$ & $100 \pm 1$ \\
\hline R369 & $48^{5} / 18^{4}$ & $132 \pm 2^{a . b}$ & $106 \pm 2$ & $100 \pm 1$ & $99 \pm 1$ \\
\hline R371 & $48^{5} / 18^{4}$ & $129 \pm 1^{a . b}$ & $107 \pm 2$ & $100 \pm 2$ & $102 \pm 2$ \\
\hline R370 & $48^{6} / 18^{4}$ & $107 \pm 2^{b}$ & $140 \pm 1^{c}$ & $100 \pm 1$ & $101 \pm 2$ \\
\hline R356 & $48^{1 / 48^{3}}$ & $105 \pm 2$ & $104 \pm 2$ & $100 \pm 3$ & $102 \pm 2$ \\
\hline R372 & $48^{7} / 0^{2}$ & $103 \pm 2$ & $102 \pm 2$ & $100 \pm 2$ & $97 \pm 2$ \\
\hline
\end{tabular}

Hours of binocular optokinetic stimulation $\left(P \rightarrow A_{L}\right)$.

${ }^{2}$ Delay between the end of optokinetic stimulation and perfusion of rabbit.

${ }^{3}$ After optokinetic stimulation, the rabbit was surrounded by a stationary visual environment.

- After optokinetic stimulation, the rabbit was maintained in total darkness.

${ }^{s}$ Hours of monocular optokinetic stimulation $\left(A \rightarrow P_{R}\right)$.

${ }^{6}$ Hours of monocular optokinetic stimulation $\left(P \rightarrow A_{L}\right)$.

${ }^{7}$ Hours of restraint with both eyes occluded by translucent Ping-Pong balls.

${ }^{a}$ Difference between optical density of neurons in the left dorsal cap and left medial accessory olive is significant, $p=0.0001$.

${ }^{b}$ Difference between optical density of neurons in the left dorsal cap and right dorsal cap is significant, $p-0.0001$.

'Difference between optical density of neurons in the right dorsal cap and right medial accessory olive is significant, $p=0.0001$.

that section. The optical densities of each group of 30 neurons were summed to give four composite optical densities. Ratios of optical density were computed for each group, with the optical density of the 30 "control" sections comprising the left medial accessory olive used as the denominator.

Statistics. Statistical comparisons were made between the optical densities measured of the four groups of $\mathbf{3 0}$ olivary neurons measured in each rabbit. The mean optical densities of these four different groups of olivary neurons were treated as independent samples and compared with a two-tailed $t$ test (Dowdy and Wearden, 1983). For the purposes of the present experiment differences between groups were considered significant at $P=0.0001$, corresponding to $t \geq 4.2, n=58$.

\section{Results}

Binocular optokinetic stimulation and the increased expression of CRF in dorsal cap neurons. A total of nine rabbits received binocular optokinetic stimulation ( 5 degrees $/ \mathrm{sec}$ ) for $48 \mathrm{hr}$. Two of those rabbits, R358 and R345, were ancsthetized and killed immediately after the optokinetic stimulation was stopped (Table 1). The immunostaining of the dorsal caps demonstrated a large increase in optical density of neurons in the right dorsal cap (177\% in $\mathrm{R} 358,157 \%$ in $\mathrm{R} 345$ ) relative to control neurons in the left medial accessory olive (Fig. 2A, Table 1). The large increase in expression of CRF in the right dorsal cap was seen only in the caudal part of the dorsal cap that is known to encode horizontal optokinetic stimulation. The microdensitometric techniques that we used measured 10 neurons at three different rostral-caudal levels in the most caudal $600 \mu \mathrm{m}$ of the dorsal cap. In each section we deliberately tried to measure cells distributed throughout the entire extent of the dorsal cap. A section through the caudal dorsal cap encompasses approximately 20 30 neurons. The total population of the dorsal cap that is sensitive to horizontal optokinetic stimulation includes approximately 500 neurons. We measured the oplical density of approximately $6 \%$ of the total population.

$C R F$ decay following increased expression. One rabbit, R356, was exposed to binocular stimulation for $48 \mathrm{hr}$ followed by an additional $48 \mathrm{hr}$ of restraint in the illuminated, but stationary drum (Fig. 2B, Table 1). In this case the stimulus-evoked increased expression of CRF had returned to near background levels (Fig. $2 B_{1}$ ), roughly agreeing with previous measurements on the decay in the CRF mRNA following optokinetic stimulation (Barmack and Young, 1990). Dorsal cap neurons in control sections that were not incubated in the rabbit $\alpha$-rat/human CRF serum were not stained (Fig. $2 B_{2}$ ).

Influence of postoptokinetic stimulation conditions on CRF expression. Six rabbits received binocular optokinetic stimulation for $48 \mathrm{hr}$. They were anesthetized and killed 16-18 hr after the cessation of optokinetic stimulation. During this poststimulation period they were maintained under different conditions of visual stimulation (light or dark) and different amounts of restraint (head fixed or totally free to move). After receiving

\footnotetext{
Figure 2. Influence of binocular optokinetic stimulation on CRF expression in dorsal cap neurons. $A$, Binocular optokinetic stimulation (OKS) was given for $48 \mathrm{hr}\left(P \rightarrow A_{L}\right)$ and the rabbit, R345, was immediately killed. Histological section through the caudal dorsal cap in $A_{l}$ corresponds to the rostral-caudal level of Figure $1 B_{4}$. Section in $A_{2}$ corresponds to the rostral-caudal level of Figure $1 B_{3}$. $B$, Binocular stimulation given to R356 for $48 \mathrm{hr}\left(P \rightarrow A_{L}\right)$ followed by an additional period of $48 \mathrm{hr}$ during which the rabbit was restrained in the stationary, illuminated optokinetic drum. The section in $B_{l}$ was taken from the middle dorsal cap and corresponds to the rostral-caudal level of Figure $1 B_{2}$. Note slight increase in CRF immunoreactivity in both the left and right dorsal caps. The control section in $B_{2}$ was not incubated in $\alpha$-rat/human CRF serum. This section corresponds to the rostral-caudal level of Figure $1 B_{3}$. Scale bar in $B_{2}$ applies to all four sections.
} 

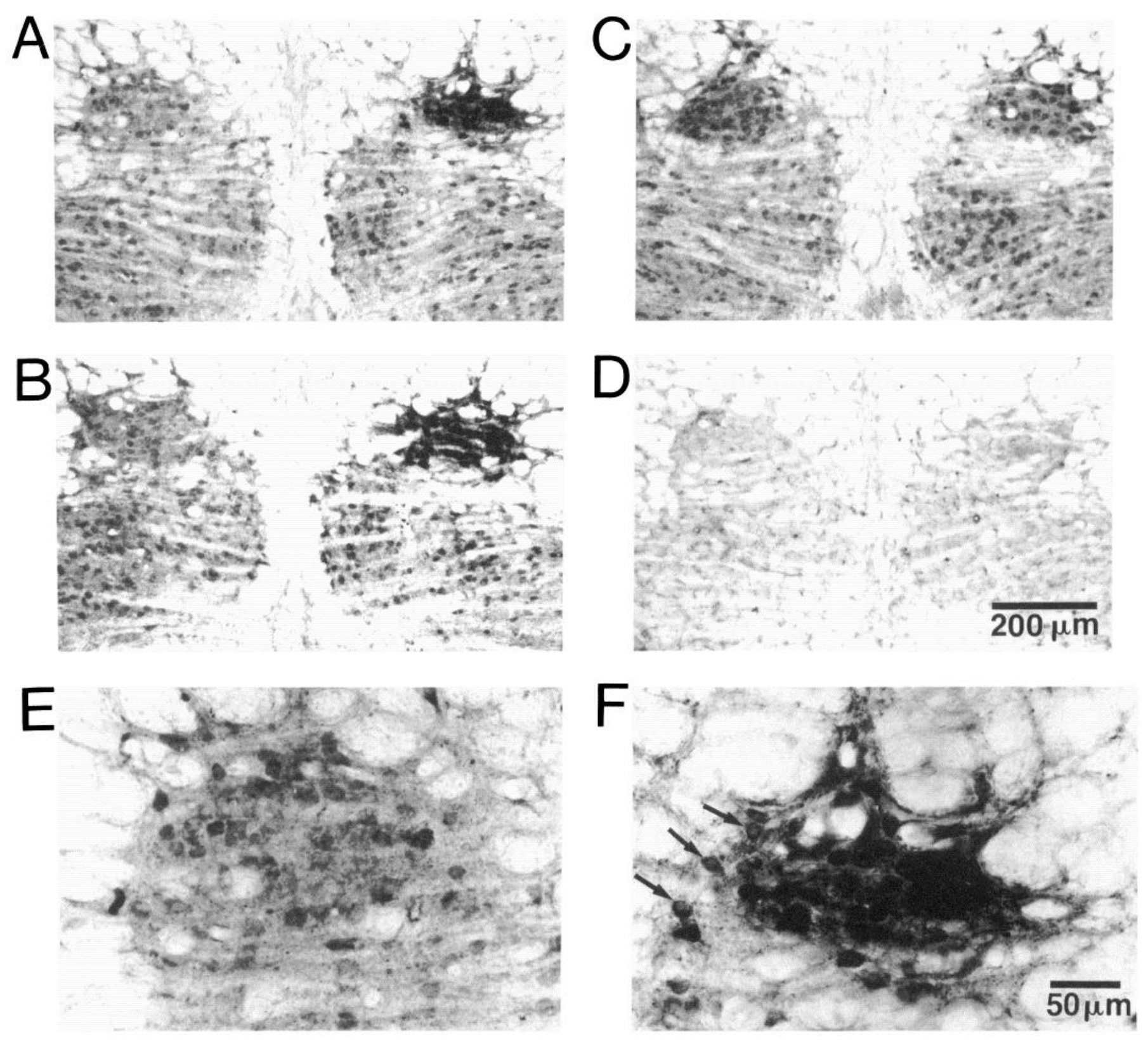

Figure 3. Binocular optokinetic stimulation and expression of CRF following a poststimulus exposure to a stationary illuminated environment for $16 \mathrm{hr}$. Binocular optokinetic stimulation was given to $\mathrm{R} 367$ for $48 \mathrm{hr}\left(\mathrm{P} \rightarrow \mathrm{A}_{\mathrm{L}}\right)$. Following this stimulation the rabbit was maintained in the stationary, illuminated optokinetic drum for $16 \mathrm{hr}$ prior to death. $A$, Section taken from the caudal dorsal cap at level of Figure $1 B_{5}$. $B$, This section was taken $400 \mu \mathrm{m}$ more rostral than section in $A$ and corresponds to the rostral-caudal level of Figure $1 B_{3}$. $C$, Section taken $400 \mu \mathrm{m}$ more rostral than $B$, about $150 \mu \mathrm{m}$ rostral to the rostral-caudal level of Figure $1 B_{2} . D$, Control section taken $80 \mu \mathrm{m}$ rostral to the section in $A$, but not incubated in $\alpha$-rat/human CRF serum. $E$ and $F$, Higher magnification of the dorsal caps in $A$. The arrows in $F$ indicate neurons with cytoplasmic, but not nuclear, staining for CRF. Scale bar in $D$ applies to $A-D$; scale bar in $F$ applies to $E$ and $F$.

Figure 4. Effects of binocular optokinetic stimulation and poststimulus visual stimulation in the absence of restraint on CRF expression. Binocular optokinetic stimulation was given to $\mathrm{R} 351$ for $48 \mathrm{hr}\left(\mathrm{P} \rightarrow \mathrm{A}_{\mathrm{L}}\right)$. Following this stimulation the rabbit was maintained unrestrained in an illuminated transport cage for $16 \mathrm{hr}$ prior to death. $A$, Section taken from the caudal dorsal cap at level of Figure $1 B_{3} . B$, This section was taken $80 \mu \mathrm{m}$ rostral to section in $A$. $C$, Section taken at the rostral-caudal level of Figure $1 B_{1}$, just caudal to the ventrolateral outgrowth. $D$, Control section taken 80 $\mu \mathrm{m}$ caudal to the section in $C$, but not incubated in $\alpha$-rat/human CRF serum. The arrows indicate the dorsal and lateral borders of the dorsal cap characteristic of the ventrolateral outgrowth. Scale bar in $D$ applies to all panels. 

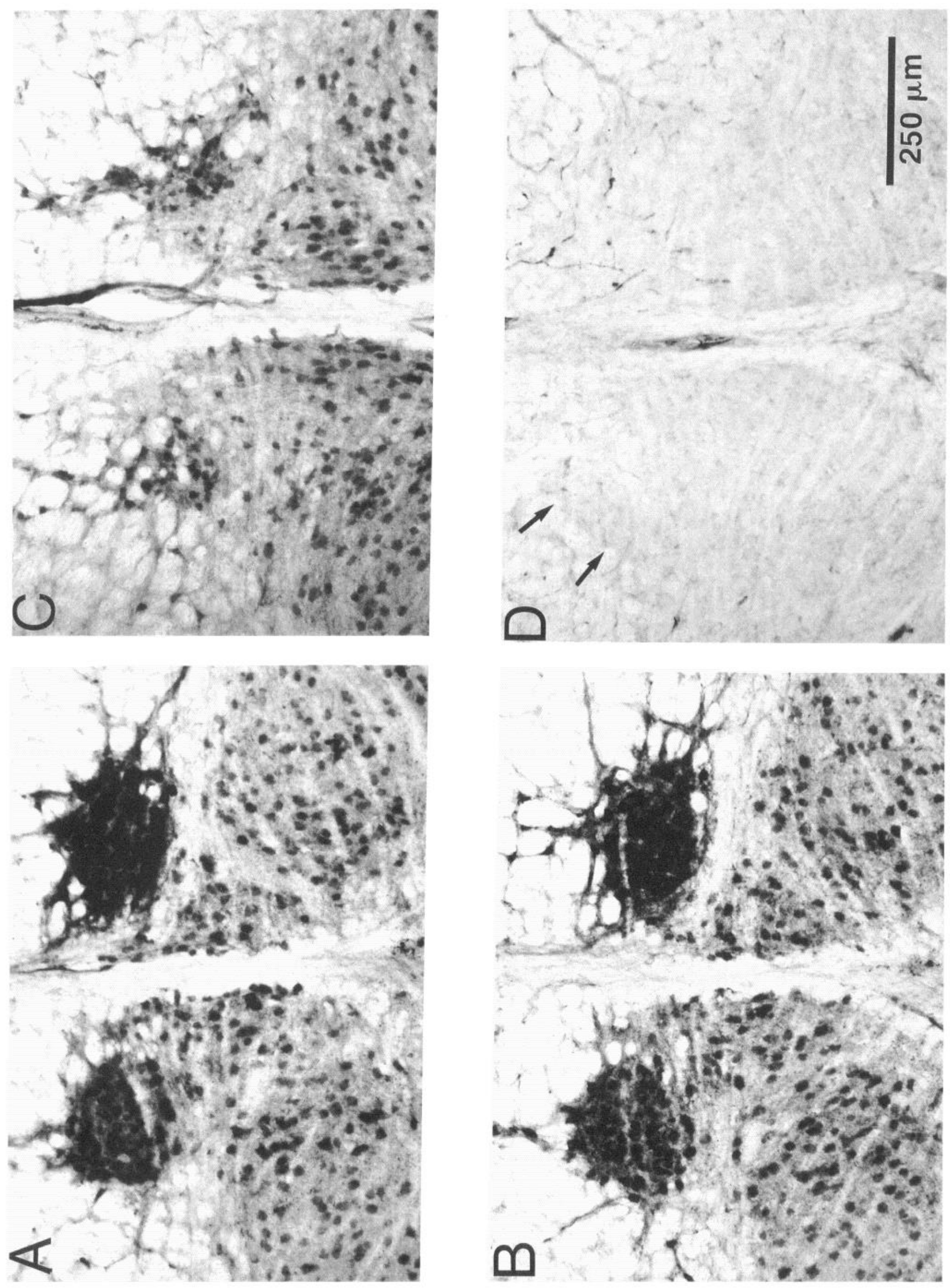

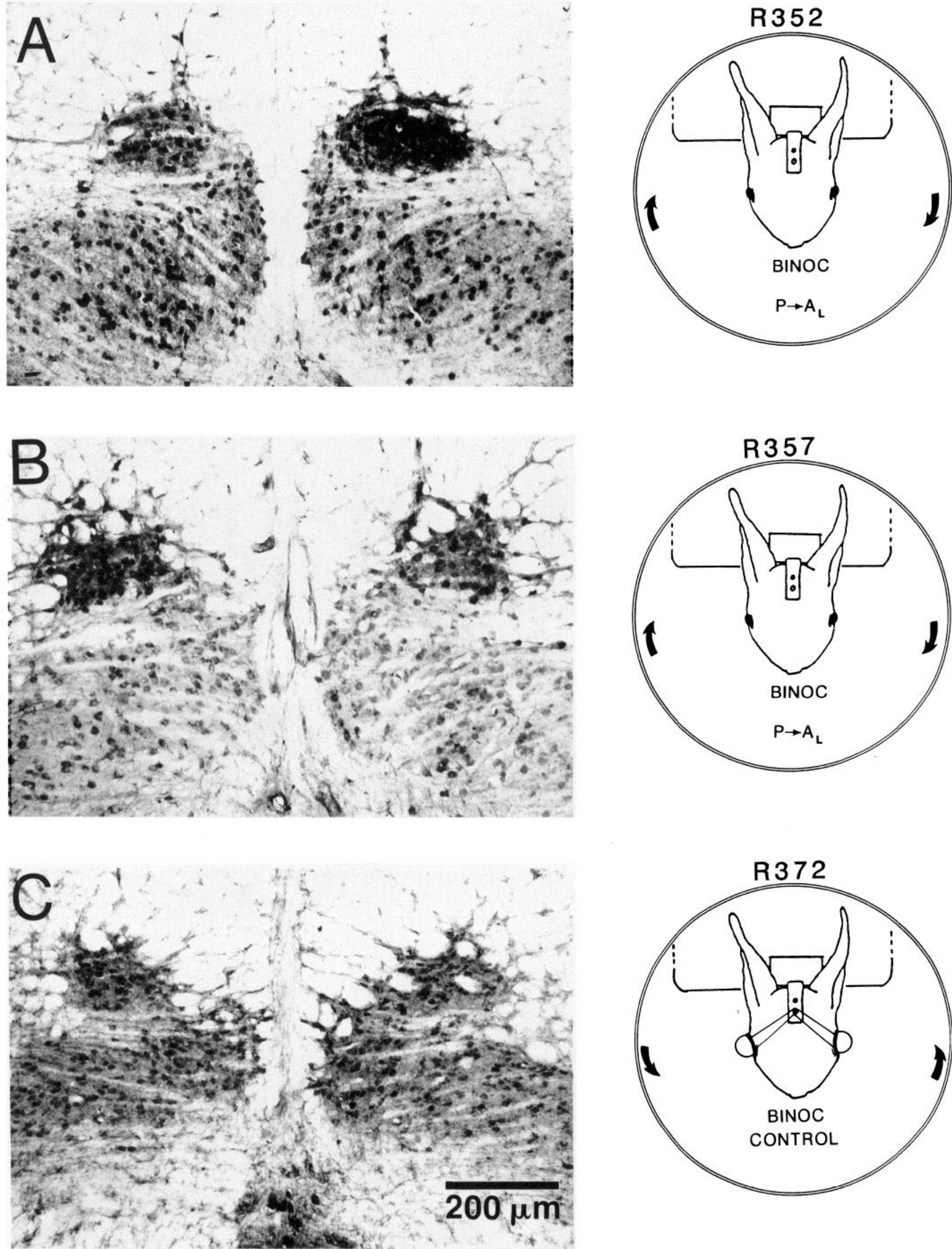
binocular optokinetic stimulation for $48 \mathrm{hr}\left(\mathrm{P} \rightarrow \mathrm{A}_{\mathrm{L}}\right), \mathrm{R} 367$ was restrained for $16 \mathrm{hr}$ in an illuminated, but stationary, optokinetic drum (Fig. 3). Immunostaining revealed more intense cellular optical density in the right caudal dorsal cap (Fig. $3 A, B$ ). Cells located in the rostral dorsal cap (Fig. $3 C$ ) evinced no difference in optical density compared to neurons of the medial accessory olive. This confirms the specificity of the optokinetically evoked increase in CRF expression was restricted to olivary ncurons in the region of the dorsal cap that is known to be responsive to horizontal optokinetic stimulation. Higher magnifications of the dorsal cap neurons (Fig. $3 E, F$ ) showed that the somata were densely labeled, but that the nuclei were not. Hence, our quantitative estimates of neuronal expression of CRF intensity probably understated the relative differences in expression of CRF in "stimulated" and "unstimulated" neurons, by the inclusion of the CRF-free nuclei (see arrows, Fig. $3 F$ ). At higher magnification it is apparent that many cellular processes within the dorsal cap also contained increased amounts of CRF. The CRF in these processes was excluded by our quantitative measurements that were restricted to the somata.

Another rabbit, R351, received binocular optokinetic stimulation for $48 \mathrm{hr}\left(\mathrm{P} \rightarrow \mathrm{A}_{\mathrm{L}}\right)$ and subsequently was maintained without restraint for $16 \mathrm{hr}$ in an illuminated transport cage (Fig. 4). In this case therc was a difference in the expression of CRF between the optokinetically "stimulated" (138\%) and "disfacilitated" (113\%) dorsal caps (Fig. 4, Table 1). Neurons in the optokinetically "stimulated" dorsal cap expressed more CRF than did control neurons in the medial accessory olive. However, the expression of CRF in the "disfacilitated" dorsal cap was not statistically greater than that of the control neurons in the medial accessory olive (Table 1). Again, histological sections taken through more rostral regions of the dorsal cap, the part of the dorsal cap that is not activated by horizontal optokinetic stimulation, contained neurons whose optical density was equivalent to that of neurons in the medial accessory olive (Fig. $4 C)$.

Another rabbit, R352, received binocular optokinetic stimulation for $48 \mathrm{hr}\left(\mathrm{P} \rightarrow \mathrm{A}_{\mathrm{L}}\right)$ and subsequently was restrained for $16 \mathrm{hr}$ in the illuminated but stationary optokinetic drum. This led to a large increase in the optical density of neurons in the right dorsal cap (175\%) and a smaller, but statistically insignificant, increase in the optical density of neurons in the left dorsal cap (116\%) (Fig. 5A, Table 1).

However, when different postoptokinetic conditions were used, completely different relative amounts of optical density measurements were obtained. Three rabbits, R357, R361, R362, received binocular optokinetic stimulation for $48 \mathrm{hr}\left(\mathrm{P} \rightarrow \mathrm{A}_{\mathrm{L}}\right)$ (Table 1). After the optokinetic stimulation was stopped, these rabbits were restrained in total darkness in the stationary optokinetic drum for additional $18 \mathrm{hr}$. This caused a nearly symmetrical increase in the optical density of both dorsal caps. One such case, R357, is illustrated in Figure 5B. As an additional control, one rabbit, R372, was placed in the optokinetic drum wearing Ping-Pong ball occluders. After $48 \mathrm{hr}$ of optokinetic drum rotation $\left(P \rightarrow A_{R}\right)$ the rabbit was anesthetized and killed. The optical density of neurons in both dorsal caps was no different than that of neurons in the medial accessory olive (Fig. $5 C)$.

The implication of these data is that during the postoptokinetic stimulation period that followed $48 \mathrm{hr}$ of binocular optokinetic stimulation, there was a decay in CRF expression in the stimulated dorsal cap. Conversely, during this period there was a rebound in expression of CRF in the dorsal cap that was disfacilitated. This rebound of CRF expression in the disfacilitated dorsal cap appears to have been promoted by postoptokinetic stimulation restraint in the dark (Table 1, R357, R361, and R362). There are two general explanations for the rebound in CRF expression observed following binocular optokinetic stimulation. (1) In the peripheral explanation, optokinetic stimulation in anterior $\rightarrow$ posterior direction decreases the activity of neurons in the contralateral dorsal cap. The rebound occurs because these olivary neurons are released from this disfacilitatory influence when the optokinetic stimulation stops. The actual location within the peripheral visual olivocerebellar circuitry of the presumed increased excitability could be at the level of the directionally selective retinal ganglion cell, the nucleus of the optic tract or the dorsal cap (or at all three locations). (2) In the central explanation, the rebound at the end of binocular stimulation is due to a release from a disfacilitatory signal generated by neurons in the contralateral (excited) dorsal cap. This excitatory signal could be conveyed centrally to the cerebellum. The signal could flow from the cerebellum to the ipsilateral nucleus prepositus hypoglossi and eventually reach the contralateral dorsal cap as a disfacilitatory signal (Barmack et al., 1993). Then, when the excitatory signal is withdrawn from the excited dorsal cap, the disfacilitatory central signal would be withdrawn from the disfacilitated dorsal cap. A choice between these two general explanations is possible by using monocular optokinetic stimulation.

Monocular optokinetic stimulation and the increased expression of CRF in dorsal cap neurons. Two rabbits, $\mathrm{R} 369$ and $\mathrm{R} 371$, received monocular optokinetic stimulation for $48 \mathrm{hr}\left(A \rightarrow P_{R}\right)$ (Table 1). After the optokinetic stimulation was stopped, these rabbits were restrained in the optokinetic drum for an additional $18 \mathrm{hr}$ in total darkness. Thus, the right eyes and the left dorsal caps received a $48 \mathrm{hr}$ "disfacilitatory" optokinetic stimulus while the left eyes and right dorsal caps were presumably not stimulated because of the Ping-Pong ball occluders. At death, the optokinetically disfacilitated left dorsal caps cvinced an increased expression of CRF (R371, 129\%; R369, 132\%) (Fig. $6 A, B$; Table 1) while the CRF in neurons of the optokinetically unstimulated right dorsal caps were near spontaneous levels of expression (R371, 107\%; R369, 106\%). Thus, the rebound in CRF expression could be evoked in the disfacilitated dorsal cap

\section{$\leftarrow$}

Figure 5. Effects of binocular optokinetic stimulation and postoptokinetic visual stimulation on CRF expression in restrained rabbits. $A$, Binocular optokinetic stimulation was given to $\mathrm{R} 352$ for $48 \mathrm{hr}\left(P \rightarrow A_{L}\right)$. Following this stimulation the rabbit was restrained in the optokinetic drum for an additional $16 \mathrm{hr}$ before death. Section was taken from a rostral-caudal level corresponding to Figure $1 B_{3} . B$, Binocular optokinetic stimulation was given to R357 for $48 \mathrm{hr}\left(P \rightarrow A_{L}\right)$. Following this stimulation the rabbit was restrained in the dark for an additional $18 \mathrm{hr}$ before death. Section was taken from a rostral-caudal level corresponding to Figure $1 B_{3}$, about $100 \mu \mathrm{m}$ more rostral to section $A$. $C$, R372 was placed in the moving optokinetic drum for $48 \mathrm{hr}$ while wearing contact occluders binocularly. Following this stimulation the rabbit was immediately killed. Section was taken from a rostral-caudal level corresponding to Figure $1 B_{4}$. Scale bar in $C$ applies to all three sections. 

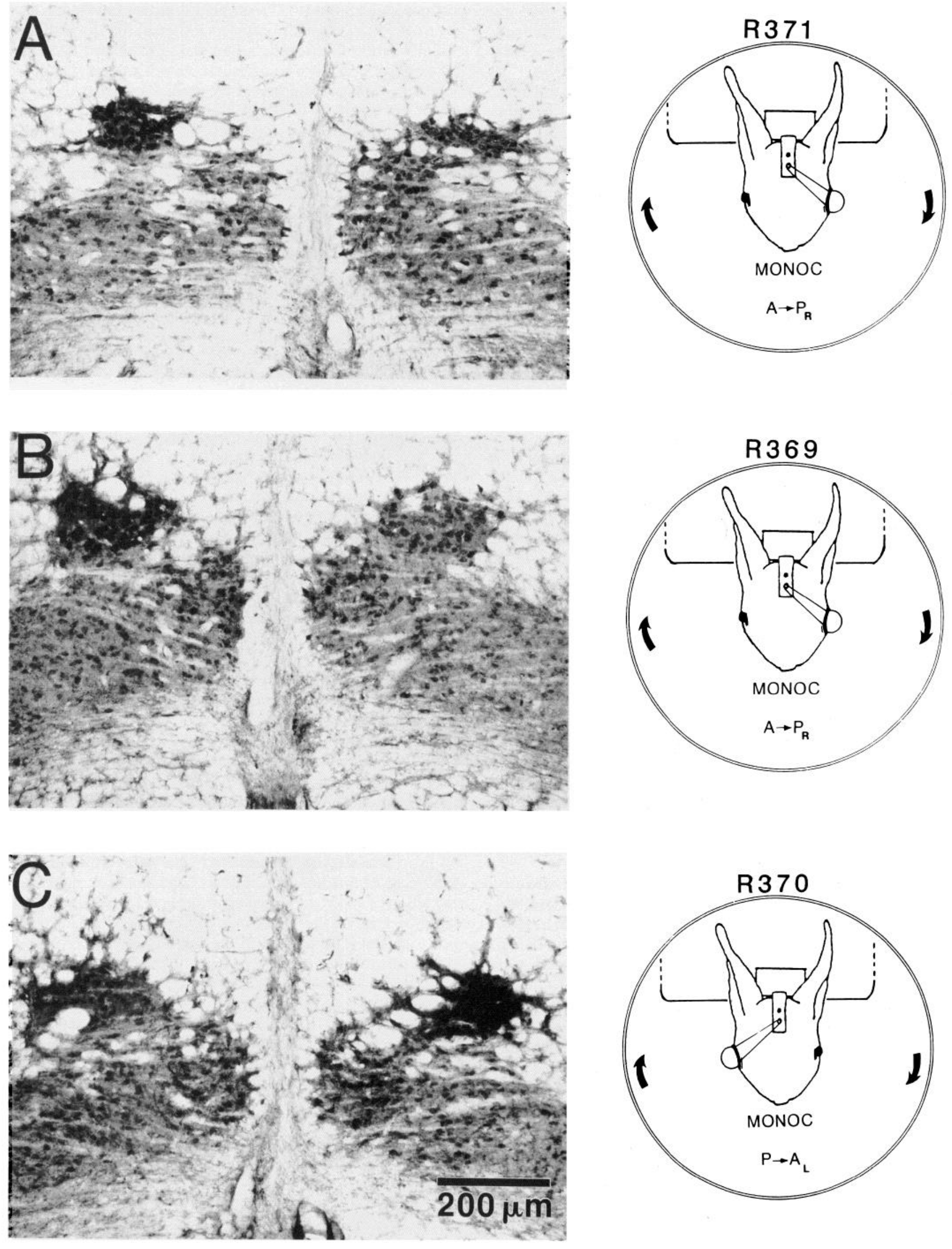
merely by anterior $\rightarrow$ posterior stimulation of the contralateral eye. It did not require posterior $\rightarrow$ anterior stimulation of the ipsilateral eye.

Another rabbit, R370, received monocular optokinetic stimulation for $48 \mathrm{hr}\left(\mathrm{P} \rightarrow \mathrm{A}_{\mathrm{L}}\right)$ in the "excitatory" direction with respect to the left eye (Fig. $6 \mathrm{C}$ ). After the optokinetic stimulation was stopped, this rabbit was restrained in the optokinetic drum for an additional $18 \mathrm{hr}$ in total darkness. This lead to an increased expression of CRF in neurons in the optokinetically stimulated right dorsal cap (140\%) and a near baseline level of expression of CRF in neurons in the left dorsal cap (107\%) (Fig. $6 C$, Table 1). This shows that optokinetically evoked excitation of dorsal cap neurons on one side of the brainstem is neither necessary nor sufficient to produce the rebound effect in dorsal cap neurons on the other side. Of the two general classes of explanation for the rebound effect, peripheral and central, our data support the peripheral hypothesis.

\section{Discussion}

Optokinetically evoked increased expression in CRF: methodological considerations. Binocular, unidirectional optokinetic stimulation at a stimulus velocity of 5 degrees/sec increased the expression of CRF in dorsal cap neurons that were excited by this stimulus. This observation agrees with previous measurements on the transcription and subsequent decay in CRF mRNA following optokinetic stimulation (Barmack and Young, 1990).

There are a number of sources of variability in this experiment that could have influenced our results. First, the optokinetic stimulus of 5 degrees/sec evokes reflexive eye movements with an initial "slow phase" of approximately 4 degrees/sec, creating a retinal slip velocity of 1 degrec/scc. However, during the course of $48 \mathrm{hr}$ of optokinetic stimulation, a slow adaptation occurs and the velocity of the optokinetically evoked eye movements decreases (Barmack and Nelson, 1987). The course of this adaptation varies for each rabbit and this can lead to variability in the actual retinal slip velocity experienced by each rabbit. Second, we have used a rabbit $\alpha$-rat/human CRF serum to examine rabbit tissue. Our control experiments, in which this primary antibody was deleted, demonstrated that the staining of inferior olivary neurons was specific, although there was some background staining of the blood vessels in the region surrounding the inferior olive (P. Errico and N. H. Barmack, unpublished observations). Third, processes of olivary neurons, both dendrites and axons were also labeled by the antiserum. Some of these processes overlap the somata whose optical density was measured and therefore could have influenced the measurements by an undetermined amount. An alternative method of measurement might have compared the optical density of a defined region of each dorsal cap. However, that method would have underestimated the differences in olivary staining by including extracellular regions in which there was no reason to expect the presence of CRF. Fourth, although we measured the optical density of individual dorsal cap as well as control olivary neurons in the medial accessory olive in each tissue section, at present we do not have a method of quantifying our measurements in terms of the actual amount of CRF present in these neurons. Fifth, we do not know the extent to which the change in CRF expression in olivary neurons could have been influenced by possible increases or decreases in the axonal transport of CRF from olivary neuronal somata toward the climbing fiber terminals in the cerebellum. In fact, one reason for investigating the possible influence of allowing $16-18 \mathrm{hr}$ to elapse following optokinetic stimulation was our expectation that such a delay might allow climbing fiber terminals of stimulated olivary neurons to become "loaded" with CRF. We hoped that this might provide a functional marker for climbing fiber terminals. This did not occur given the resolution of our techniques. Our inference is that CRF is released from terminals as rapidly as it is transported to them. Since the optokinetically evoked increase in CRF is preceded by a large increase in CRF mRNA transcription (Barmack and Young, 1990), we conclude that our observations in the present experiment reflect increased expression of CRF and not simply a stimulus-evoked regulation of its axonal transport.

Possible role of $C R F$ in olivocerebellar plasticity. At the level of the cerebellum it is possible that the release of CRF by climbing fiber terminals and its binding to CRF receptors on Purkinje cells (Wynn et al., 1984; DeSouza et al., 1985; DeSouza, 1987) might contribute to both the short-term and long-term climbing fiber-evoked modulation of the discharge of Purkinje cells and to the consequent plasticity of eye movements evoked by visual olivocerebellar activity.

Although cerebellar Purkinje cells are endowed with CRF receptors, the mechanisms by which altered expression of CRF could influence either immediate or long-term Purkinje cell activity are not understood. The exogenous application of CRF onto hippocampal pyramidal cells (Aldenhoff et al., 1983) and cerebellar Purkinje cells (Bishop, 1990; Bishop and King, 1992; Fox and Gruol, 1993) causes a modest increase in the discharge of these neurons, in part, by reducing the amplitude of afterhyperpolarization following action potentials. Intraventricular injections of CRF in the anesthetized rat also increase the spontaneous discharge rate of neurons in the locus coeruleus (Valentino and Foote, 1988). However, in neither of these instances is it certain that the CRF-evoked increases in discharge rate were CRF receptor mediated. In frontal cortex, as well as the amygdala, activation of CRF receptors leads to increased activity of adenylate cyclase, implicating CAMP in the central actions of CRF (Wynn et al., 1984).

It is possible that CRF could influence the responses of cerebellar Purkinje cells mediated by receptors for other synaptic transmitters that may be co-released with CRF. For example, cerebellar Purkinje cells are endowed with quisqualate receptors (Kano and Kato, 1988; Kano et al., 1988). When glutamate is iontophoretically applied to Purkinje cells in conjunction with climbing fiber input, there is a subsequent long-term depression

\footnotetext{
Figure 6. Effects of monocular optokinetic stimulation and postoptokinetic visual stimulation on CRF expression in restrained rabbits. $A$, Monocular optokinetic stimulation was given to $\mathrm{R} 371$ for $48 \mathrm{hr}\left(A \rightarrow P_{R}\right)$. Following this stimulation, the rabbit was restrained in the dark for an additional $18 \mathrm{hr}$ before death. Section was taken from a rostral-caudal level corresponding to Figure $1 B_{4}$, $B$, As in $A$, monocular optokinetic stimulation was given to $\mathrm{R} 369$ for $48 \mathrm{hr}\left(A \rightarrow P_{R}\right)$. Following this stimulation the rabbit was restrained in the dark for an additional 18 hr before death. Section was taken from a rostral-caudal level corresponding to Figure $1 B_{3}$. $C$, Monocular optokinetic stimulation was given to R370 for 48 $\mathrm{hr}\left(P \rightarrow A_{L}\right)$. Following this stimulation the rabbit was restrained in the dark for an additional $18 \mathrm{hr}$ before death. Section was taken from a rostralcaudal level corresponding to Figure $1 B_{3}$. The scale bar in $C$ applies to all sections.
} 
of Purkinje cell responses to iontophoretically applied glutamate or to responses evoked by electrical stimulation of parallel fibers (Crepel and Krupa, 1988; Kano and Kato, 1988; Kano et al., 1988). We have looked for such an effect using in vitro tissue slice recording $(\mathrm{N}$. H. Barmack and R. Yang-Li, unpublished observations), so far without observing any significant interaction between the coapplication of CRF and excitatory amino acids.

It seems unlikely that the major contribution of CRF receptors on Purkinje cells would be to contribute to a modest increase in excitability of these neurons. The excitatory postsynaptic potentials evoked by climbing fibers are among the largest observed in central neurons, depolarizing these neurons by 5-20 $\mathrm{mV}$ (Eccles et al., 1966). Immediately following a climbing fiber response, the Purkinje cell is "inactivated" (Granit and Phillips, 1956). This would suggest that if CRF were to function by reducing afterhyperpolarizations, then it would have a longer time constant of action to influence the afterhyperpolarizations of action potentials that occur following the period of climbing fiber-induced inactivation. Alternatively, CRF may be coupled to even longer-term subcellular events. Future experiments should focus on defining which subcellular events might be dependent on activation of CRF receptors.

Peripheral origin of rebound in expression of CRF in dorsal cap neurons following optokinetic stimulation. We initiated this experiment to explore the possibility that CRF expression could be related to olivary activity and that this enhanced expression could, in part, be responsible for long-term changes in cerebellar function. However, we observed indirectly that some of these long-term changes may actually reflect changes in preolivary synaptic function. The key observation leading to this conclusion was the rebound in expression of CRF in dorsal cap neurons that were disfacilitated during either binocular or monocular optokinetic stimulation. Our data ruled out the possibility that this rebound in CRF expression is caused by a centrally generated signal, originating from dorsal cap neurons that are excited by posterior $\rightarrow$ anterior optokinetic stimulation.

The actual location within the peripheral visual olivocerebellar circuitry of this postoptokinetic increase in excitability, following disfacilitatory optokinetic stimulation, could be at the level of the directionally selective retinal ganglion cell, the nucleus of the optic tract, or the dorsal cap (or at all three locations). Synaptic mechanisms that could account for the observed changes in preolivary synaptic function include stimulus-evoked expression of receptors, transmitters, or synaptic transporters. These possible mechanisms are all amenable to further experimental analysis.

\section{References}

Aldenhoff JB, Gruol DL, Rivier J, Vale W, Siggins GR (1983) Corticotropin releasing factor decreases postburst hyperpolarizations and excites hippocampal neurons. Science 221:875-877.

Alley K, Baker R, Simpson JI (1975) Afferents to the vestibulo-cerebellum and the origin of the visual climbing fibers in the rabbit. Brain Res 98:582-589.

Barmack NH (1979) Immediate and sustained influences of visual olivocerebellar activity on eye movement. In: Posture and movement (Talbott RE, Humphrey DR, eds), pp 123-167. New York: Raven.

Barmack NH, Hess DT (1980a) Multiple-unit activity evoked in dorsal cap of inferior olive of the rabbit by visual stimulation. J Neurophysiol 43:151-164.

Barmack NH, Hess DT (1980b) Eye movements evoked by microstimulation of dorsal cap of inferior olive in the rabbit. J Neurophysiol $43: 165-181$.
Barmack NH, Nelson BJ (1987) Influence of long-term optokinetic stimulation on eye movements of the rabbit. Brain Res 437:111-120.

Barmack NH, Simpson JI (1980) Effects of microlesions of dorsal cap of inferior olive of rabbits on optokinetic and vestibulo-ocular reflexes. J Neurophysiol 43:182-205.

Barmack NH, Young WS III (1990) Optokinetic stimulation increases corticotropin-releasing factor mRNA in inferior olivary neurons of rabbits. J Neurosci 10:631-640.

Barmack NH, Fagerson M, Errico P (1993) Cholinergic projection to the dorsal cap of the inferior olive of the rat, rabbit and monkey. $J$ Comp Neurol 328:263-281.

Bishop GA (1990) Neuromodulatory effects of corticotropin releasing factor on cerebellar Purkinje cells: an in vivo study in the cat. Neuroscience 39:251-257.

Bishop GA, King JS (1992) Differential modulation of Purkinje cell activity by enkephalin and corticotropin releasing factor. Neuropeptides 22:167-174.

Cha CI, Foote SL (1988) Corticotropin-releasing factor in olivocerebellar climbing-fiber system of monkey (Saimiri sciureus and Macaca fascicularis): parasagittal and regional organization visualized by immunohistochemistry. J Neurosci 8:4121-4137.

Crepel F, Krupa M (1988) Activation of protein kinase C induces a long-term depression of glutamate sensitivity of cerebellar Purkinje cells. An in vitro study. Brain Res 458:397-401.

Cummings S, Sharp B, Elde R (1988) Corticotropin-releasing factor in cerebellar afferent systems: a combined immunohistochemistry and retrograde transport study. J Neurosci 8:543-554.

Cummings SL, Young WS III, Bishop GA, De Souza EB, King JS (1989) Distribution of corticotropin-releasing factor in the cerebellum and precerebellar nuclei of the opossum: a study utilizing immunohistochemistry, in situ hybridization histochemistry, and receptor autoradiography. J Comp Neurol 280:501-521.

Desclin JC (1974) Histological evidence supporting the inferior olive as the major source of cerebellar climbing fibers in the rat. Brain Res 77:365-384.

DeSouza EB (1987) Corticotropin-releasing factor receptors in the rat central nervous system: characterization and regional distribution. $J$ Neurosci 7:88-100.

DeSouza EB, Insel TR, Perrin MH, Rivier J, Vale WW, Kuhar MJ (1985) Corticotropin-releasing factor receptors are widely distributed within the rat central nervous system: an autoradiographic study. $\mathbf{J}$ Neurosci 5:3189-3203.

Dowdy S, Wearden S (1983) Statistics for research. New York: Wiley.

Dufosse M, Ito M, Miyashita Y (1978) Diminution and reversal of eye movements induced by local stimulation of rabbit cerebellar flocculus after partial destruction of the inferior olive. Exp Brain Res 33: 139-141.

Eccles JC, Llinas R, Sasaki K (1966) The excitatory synaptic action of climbing fibers on the Purkinje cells of the horizontal and vertical optokinetic reflexes of the rabbit. J Physiol (Lond) 182:268-296.

Erickson RG, Barmack NH (1980) A comparison of the horizontal and vertical optokinetic refiexes of the rabbit. Exp Brain Res 40:448456.

Fox CA, Hillman DE, Siegesmund KA, Dutta CR (1967) The primate cerebellar cortex: a Golgi and electron microscopic study. In: Progress in brain research, Vol 25, The cerebellum (Fox CA, Snider RS, eds), pp 174-225. New York: Elsevier.

Fox EA, Gruol DL (1993) Corticotropin-releasing factor suppresses the afterhyperpolarization in cerebellar Purkinje neurons. Neurosci Lett 149:103-107.

Granit R, Phillips CG (1956) Excitatory and inhibitory processes acting upon individual Purkinje cells of the cerebellum in cats. J Physiol (Lond) 133:520-547.

Harkness JE, Wagner JE (1989) The biology and medicine of rabbits and rodents. Philadelphia: Lea and Febiger.

Ito M (1984) The cerebellum and neural control. New York: Raven.

Ito M, Nisimaru N, Yamamoto M (1976) Pathways for the vestibuloocular reflex excitation arising from semicircular canals of rabbits. Exp Brain Res 24:257-271.

Ito M, Jastreboff PJ, Miyashita Y (1982) Specific effects of unilateral lesions in the flocculus upon cyc movements in albino rabbits. Exp Brain Res 45:233-242.

Kano M, Kato M (1988) Mode of induction of long-term depression at parallel fibre-Purkinje cell synapses in rabbit cerebellar cortex. Neurosci Res 5:544-556. 
Kano M, Kato M, Chang HS (1988) The glutamate receptor subtype mediating parallel fibre-Purkinje cell transmission in rabbit cerebellar cortex. Neurosci Res 5:325-337.

Maekawa K, Simpson JI (1973) Climbing fiber responses evoked in vestibulocerebellum of rabbit from visual system. J Neurophysiol 36: 649-666.

Maekawa K, Takeda T (1976) Electrophysiological identification of the climbing and mossy fiber pathways from the rabbit's retina to the contralateral cerebellar flocculus. Brain Res 109:169-174.

Matute C, Wiklund L, Streit P, Cuenod M (1987) Selective retrograde labeling with $\mathbf{D}-\left[{ }^{3} \mathrm{H}\right]$-aspartate in the monkey olivocerebellar projection. Exp Brain Res 66:445-447.

Mugnaini E, Nelson BJ (1989) Corticotropin-releasing factor (CRF) in the olivo-cerebellar system and feline olivary hypertrophy. In: The olivocerebellar system in motor control (Strata P, ed), pp 187-197. Berlin: Springer.

Palkovits M, Leranth C, Gorcs T, Young WS (1987) Corticotropinreleasing factor in the olivocerebellar tract of rats: demonstration by light- and electron-microscopic immunohistochemistry and in situ hybridization histochemistry. Proc Natl Acad Sci USA 84:391 1-3915.

Powers RE, DeSouza EB, Walker LC, Price DL, Vale WW, Young WS III (1987) Corticotropin-releasing factor as a transmitter in the human olivocerebellar pathway. Brain Res 415:347-352.

Sakanaka M, Shibasaki T, Lederis K (1987a) Corticotropin-releasing factor-containing afferents to the inferior colliculus of the rat brain. Brain Res 414:68-76.

Sakanaka M, Shibasaki T, Lederis K (1987b) Corticotropin releasing factor-like immunoreactivity in the rat brain as revealed by a modified cobalt-glucose oxidase-diaminobenzidine method. J Comp Neurol 260:256-298.
Schinper J, Steinbusch WM, Vermes I, Tilders FJH (1983) Mapping of CRF-immunoreactive nerve fibers in the medulla oblongata and spinal cord of the rat. Brain Res 267:145-150.

Simpson JI, Graf W, Leonard C (1981) The coordinate system of visual climbing fibers to the flocculus. In: Developments in neuroscience, Vol 12, Progress in oculomotor research (Fuchs AF, Becker W, eds), pp 475-484. Amsterdam: Elsevier-North Holland.

Sloviter RS, Valiquette G, Abrams GM, Ronk EC, Sollas AL, Paul LA, Neubort S (1989) Selective loss of hippocampal granule cells in the mature rat brain after adrenalectomy. Science 243:535-538.

Vale W, Spiess J, Rivier C, Rivier J (1981) Characterization of a 41residue ovine hypothalamic peptide that stimulates secretion of corticotropin and beta-endorphin. Science 213:1394-1397.

Valentino RJ, Foote SL (1988) Corticotropin-releasing hormone increases tonic but not sensory-evoked activity of noradrenergic locus coeruleus neurons in unanesthetized rats. J Neurosci 8:1016-1025.

Watanabe E (1984) Neuronal events correlated with long-term adaptation of the horizontal vestibulo-ocular reflex in the primate flocculus. Brain Res 297:169-174.

Wiklund L, Toggenburger G, Cuenod M (1982) Aspartate: possible neurotransmitter in cerebellar climbing fibers. Science 216:78-79.

Wynn PC, Hauger RL, Holmes MC, Millan MA, Catt KJ, Aguilera G (1984) Brain and pituitary receptors for corticotropin releasing factor: localization and differential regulation after adrenalectomy. Peptides 5:1077-1084.

Young WS III, Walker LC, Powers RE, DeSouza EB, Price DL (1986) Corticotropin-releasing factor mRNA is expressed in the inferior olives of rodents and primates. Mol Brain Res 1:189-192. 